\title{
Modelling Growth and Productivity of Yams (Dioscorea Spp): Prospects and Problems
}

\section{C. Onwueme*}

Departments of Tropical Crop Science and of Theoretical Production Ecology, Wageningen Agricultural University, Wageningen, The Netherlands

\section{$\&$}

\section{A. J. Haverkort}

Centre for Agrobiological Research, PO Box 14, 5700 AA Wageningen, The Netherlands

(Received 13 August 1990; revised version accepted 10 January 1991)

\section{ABSTRACT}

This methodological paper recommends a modelling approach to achieve a greater understanding of the physiology of yield in yams (Dioscorea spp.), and of the influence of various ecological, biotic and planter-induced factors on the yield. Such a model would also permit the prediction of yield under various conditions, and would be a tool in land evaluation. Preference is indicated for a simple model which would not require elaborate instrumentation for validation. A scheme for such a simple model is presented. Available literature data for parameterisation of the model are reviewed and areas of information gaps and additional research needs are highlighted. It is concluded that the most pressing need is for data sets derived from wellplanned comprehensive field experiments. It is suggested that future yam field research should make use of the framework presented to facilitate comparison of results and to develop a more comprehensive model of yam growth and production.

* Present address: Federal University of Technology, Owerri, Nigeria. 


\section{INTRODUCTION}

Over 23 million tonnes of yams are produced annually world-wide, and the crop is grown on an area of about 2.5 million ha (FAO, 1989). While production occurs in nearly every part of the tropical world, yams attain their greatest importance in the humid and sub-humid lowland regions of West Africa and the Caribbean. In West Africa, D. rotundata is the most widely cultivated species, while in the Caribbean, $D$. alata is pre-eminent. Other species such as $D$. cayenensis, D. bulbifera, D. esculenta and $D$. dumetorum are grown on a much smaller scale in both regions, and elsewhere in the world. Yield levels that are currently realised in yam production are relatively low. On a world-wide basis, the crop yields only about $9 \cdot 6 \mathrm{t} / \mathrm{ha}$. compared with $14.1 \mathrm{t} / \mathrm{ha}$ for sweet potato or $14.9 \mathrm{t} / \mathrm{ha}$ for Solanum potato (FAO, 1989). Considering that the fresh yam tuber contains only about one third dry matter, this brings the average gross dry matter production worldwide to only about $3 \cdot 2 \mathrm{t} / \mathrm{ha}$. The net dry matter yield per hectare is even less in view of the large quantity of tuber material that is used for planting. The highest regional yields of fresh tuber are reported for the Solomon Islands $(28.4 \mathrm{t} / \mathrm{ha})$, and Japan (18.1 t/ha), but these are much higher than the average yields in the main producing countries such as Nigeria $(10.1 \mathrm{t} / \mathrm{ha})$ and the Cote d'Ivoire $(9 \cdot 5 \mathrm{t} / \mathrm{ha})$. Similarly, relatively high yields have been attained for yams under experimental conditions. Yields of over $30 \mathrm{t} / \mathrm{ha}$ have been recorded under field conditions (Enyi, 1972) and even higher yields of $55 \mathrm{t} / \mathrm{ha}$ have been reported for D. trifida in Guadeloupe (Martin \& Degras, 1978). Species differences also exist with respect to yied. Generally speaking, $D$. alata tends to yield more than $D$. rotundata, which is considered to be a slower-growing plant.

The indications, therefore, are that the present yields obtained by farmers are for below the potential yield of the crop. To begin to bridge this yield gap, it is important to understand how the yield that is realised comes about, and to be able to predict potential yields under various ecological conditions. Developing a model of crop growth and productivity of yams is an approach to heighten the understanding of the physiology of yield of the crop, and the impact of various ecological conditions, biotic factors and farmer-induced variables on attainable yields. The objective of this methodological paper is to outline the requirements for a simple model of yam growth and productivity, and to identify the obstacles and information gaps along the path to developing and validating such a model. Most existing crop growth models have been developed and validated for crops usually grown in temperate conditions (Haverkort \& Harris, 1987); and this exercise with yam 
review on the yam crop. Its aim is to present a framework for future yam field research, making such research more effective and efficient.

\section{PURPOSES OF THE PROPOSED MODEL}

In crop modelling, several approaches exist, necessitating models of varying complexity. For research purposes, comprehensive models are normally used. They include photosynthesis routines for the computation of total dry matter production, and respiration routines for dry matter losses due to respiration (as influenced by temperature, development, and constraints). Dry matter distribution routines related to development stage may be replaced by environment-related organ initiation and growth rate routines. Such models may be used to complete the understanding of an already wellresearched commodity. A slightly less comprehensive model is a management model, able to predict the influence and necessity of tactical cultural practices such as irrigation and pest control measures. Such a model is based on a well-defined concept of the growth of the particular crop. Its parameters should be well quantified, and it should be validated under the various production constraints for which it is supposed to perform. The model proposed here is intended to serve several purposes. First, it provides a deeper understanding and physiological explanation of how the harvested yield of yam is brought about. It will help to determine the areas where gaps exist with respect to knowledge of the crop, and it will guide researchers towards experimentation that will supply the missing information. Secondly, the model will make it possible to predict the potential yield of the crop under various ecological conditions, and as such would be a useful tool in land evaluation. It may also be able to predict the effects of various production constraints, such as drought or pest attack, as well as the effects of various cultural practices (such as sett weight, planting density, or staking) on the expected yield of yams. These purposes might be achieved by other approaches without resort to modelling. The modelling approach, however, is considered best because so little experimental data are currently available on yams. Moreover, key experiments designed and performed with the aid of a model can give results with a wider applicability. It is necessary to keep the model relatively simple, with few parameters. Such a simple model would most successfully predict yields and yield losses. Although a more complex model might give more insight into physiological processes, it also necessitates the validation of routines describing complex processes such as respiration, photosynthesis, or water status of the plants. Equipment and 
need the validation of complex processes with the aid of sophisticated equipment. Once such a simple model is firmly established, it could be extended for scientific purposes by including the description of the influence of water, disease, nutrient, and pest limitations on a wider range of crop growth processes.

\section{GROWTH AND YIELD OF THE YAM CROP}

In the next part of this paper: 'Description of a set of models of increasing complexity' and in the relational diagram (Fig. 1), three sections are distinguished. Section I describes the manner in which the final stem density is achieved. Section II describes total dry matter production, and Section III the dry matter partitioning to, and size distribution of, marketable tubers. For convenience, the same order to describe the growth and yield of the yam crop will be followed here.

Yams are normally grown in rows (usually on ridges) that are spaced about $1 \mathrm{~m}$ apart; spacing within the row ranges from $30 \mathrm{~cm}$ to $100 \mathrm{~cm}$. The sett density is therefore about $1-3 \mathrm{setts} / \mathrm{m}^{2}$. The depth of planting may vary from $1 \mathrm{~cm}$ to $10 \mathrm{~cm}$, but is usually of little consequence because the sett, with its large store of food material, can emerge conveniently from relatively great depths. The weight of each yam sett planted varies greatly depending on the production situation. For the production of large ceremonial yams in West Africa or Papua New Guinea, setts weighing up to $4 \mathrm{~kg}$ may be used for planting (Coursey, 1967), while in production with the minisett technique, the weight may be as low as $20 \mathrm{~g}$ (Okoli et al., 1982). In general, however, sett weights used in the normal production of ware yams usually range from $150 \mathrm{~g}$ to $500 \mathrm{~g}$. At a planting density of $1-3 \mathrm{setts} / \mathrm{m}^{2}$, this results in a planted sett weight of $150-1500 \mathrm{~g} / \mathrm{m}^{2}$. The actual range is usually narrower, since farming practice is that smaller setts tend to be planted closer together (e.g. 3 setts $/ \mathrm{m}^{2}$ ), while larger setts are usually planted further apart (e.g. $1 \mathrm{sett} / \mathrm{m}^{2}$ ). A working figure of $700 \mathrm{~g}$ of sett $/ \mathrm{m}^{2}$ is considered representative of most production situations for ware yams.

Emergence in yams is often poor (Onwueme, 1984). The three cardinal emergence characteristics-time from planting to emergence, uniformity of emergence, and the final percentage of emergence-all show aberrations from the typical expected pattern for field crops. The time to emergence is long. It is influenced mainly by species (being longer for $D$. rotundata than for D. alata), physiological age of the planted tuber (decreasing as the physiological age increases), and the portion of the parent tuber from which 


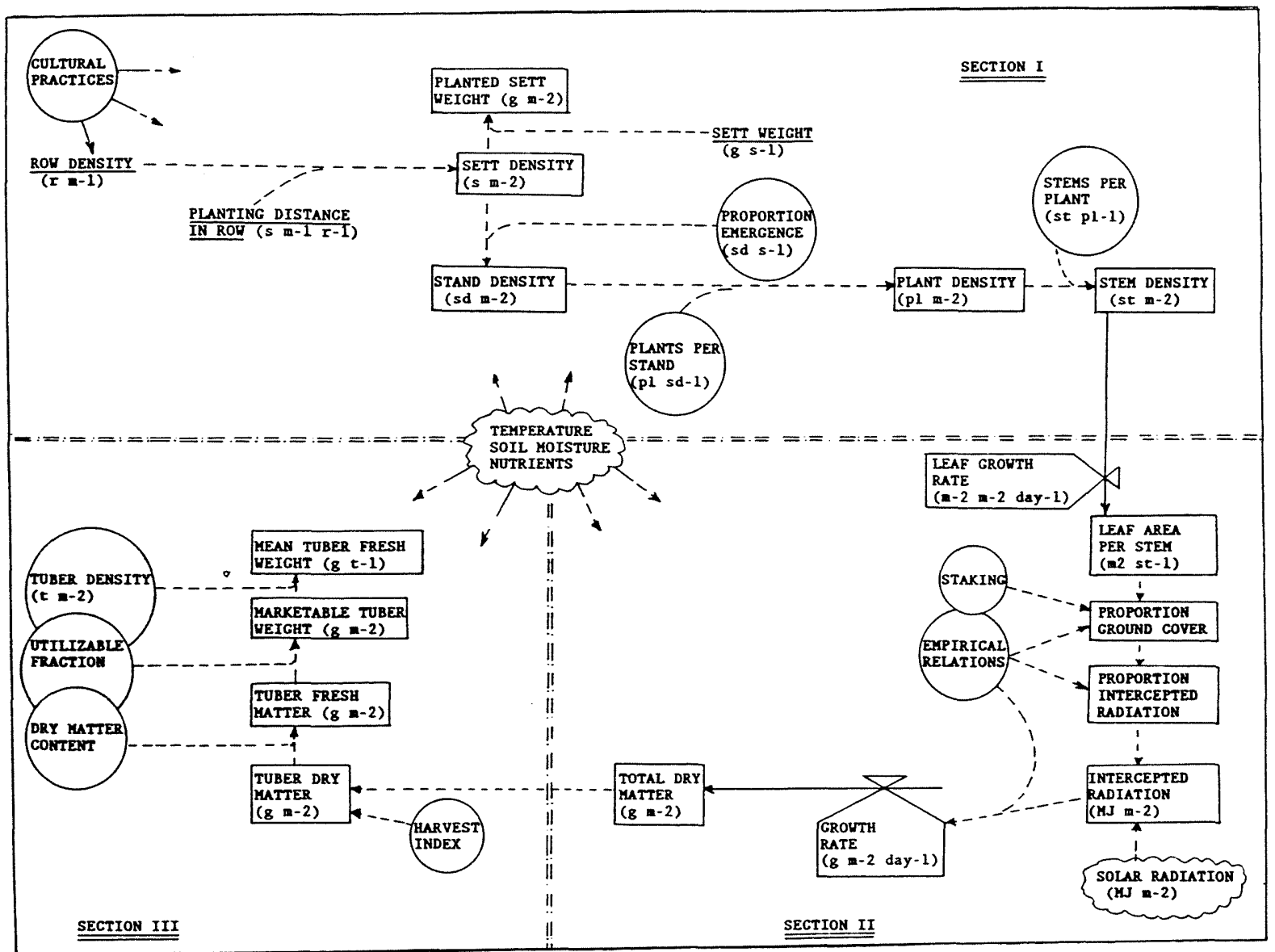

Relational diagram illustrating the interaction between cultural practices, environmental conditions and the growth and production of Boxes represent state variables, parameters (single or tabled) are underlined, valves are rates, circles and ovals are auxiliary variables and $\mathrm{s}$ are state variables not included explicitly in the model. Solid lines represent the transfer of matter, and broken lines show the transfer of information. 
weeks. In practice, in the field, the range is about 5-7 weeks, while for plantings utilising physiologically fresh tuber pieces, emergence may not occur until $12 \mathrm{cr}$ more weeks after planting due to tuber dormancy (Onwueme, 1975a). Partly because of the long time to emergence, and the influence of various factors on it, the uniformity of yam emergence is extremely low. In a farmer's field, the time gap between early emergers and late emergers may be 4 weeks or more. This is particularly so if the lot of setts used for planting is a mixture of heads, middles and tails, or if setts of various physiological ages have been used. The net effect of non-uniform emergence of yams in the field is that the plants in the field are at varying stages of development, especially with respect to the canopy. The final percentage of emergence in a yam crop depends on the cultural practices that have been adopted. If uniformly fast-emerging setts (e.g. long-stored heads or wholes) have been used, a $100 \%$ emergence is attainable, especially if the setts have been additionally protected with pesticidal dressings. Cut tuber pieces used as setts are particularly prone to deterioration after planting, and invariably result in low emergence percentages, especially when the sett weight is low. The stand density on the field is a result of the proportion of emerged plants, multiplied by the sett density.

The majority of planted yam setts will give rise to only one shoot each. Occasionally, however, a sett may give rise to two or more shoots, each of which develops its own canopy. This is particularly prone to occur if large setts have been used (Onwueme, 1972). The sett tissue between the origins of the two (or more) shoots usually disintegrates, so that each shoot now represents a separate plant. Therefore, a sett giving rise to two or more shoots on the same stand behaves as if two or more separate smaller setts had been planted on the same spot, giving rise to two or more plants per stand. This same effect is also encountered in the occasional farming practice of deliberately planting two small setts on the same spot. Each yam plant, whether arising singly from a sett, or arising as one of several plants from'the same sett, usually produces a single initial shoot that remains unbranched for several metres. As such, the number of stems per plant at soil level is almost invariably $1 \cdot 0$. In effect, stem density is usually equal to plant density. Apparent multiple stems from the same plant in the field are usually traceable below ground to multiple plants per stand.

From this it follows that the final stem density achieved in a crop may be described with the set of eqns $1-5$.

Sett density $=$ Row density $\times$ Planting density in the row

Planted sett weight $=$ Sett density $\times$ Sett weight 
Plant density $=$ Stand density $\times$ Number of plants per stand

Stem density $=$ Plant density $\times$ Number of stems per plant

Some of the crop parameters mentioned above have been quantified in research carried out in the past. Various combinations of the sett weight and sett density have been reported in the literature. Criuwa and Onwueme (1980) used sett weights of D. alata ranging from 100 to $300 \mathrm{~g}$ each, at sett densities of $1 \cdot 1-3 \cdot 3 \mathrm{setts} / \mathrm{m}^{2}$, thus giving planted sett weights ranging from 110 to $990 \mathrm{~g} / \mathrm{m}^{2}$. Proportion emergence ranged from 0.60 to 0.95 . The stand densities ranged from 0.81 stands $/ \mathrm{m}^{2}$ for the $100 \mathrm{~g}$ setts planted at 1.1 setts $/ \mathrm{m}^{2}$, to 2.8 stands $/ \mathrm{m}^{2}$ for the $300 \mathrm{~g}$ setts planted at $3.3 \mathrm{setts} / \mathrm{m}^{2}$. Plant density was not specifically determined, but could be deduced indirectly from the data provided for mean number of tubers per stand, which usually equals the mean number of plants per stand. From this, the deduced plant density ranged from 1.05 plants $/ \mathrm{m}^{2}$ for the $100 \mathrm{~g}$ setts planted at $1.1 \mathrm{setts} / \mathrm{m}^{2}$, to $4 \cdot 2$ plants $/ \mathrm{m}^{2}$ for the $300 \mathrm{~g}$ setts planted at $3 \cdot 3 \mathrm{setts} / \mathrm{m}^{2}$. Stem density was also not determined directly, but as explained earlier, it is assumed to be equal to plant density. Enyi (1972), working with D. esculenta, used planted sett weights ranging from $22 \mathrm{~g} / \mathrm{m}^{2}$ to $169 \mathrm{~g} / \mathrm{m}^{2}$. Sett density ranged from $0.74 \mathrm{setts} / \mathrm{m}^{2}$ to $1.85 \mathrm{setts} / \mathrm{m}^{2}$. Emergence and stem counts were not taken so it is not possible to calculate stand density, plant density or stem density. In experiments with $D$. rotundata and $D$. alata in Nigeria, Onwueme and Fadayomi (1980) obtained mean proportion emergence values of 0.78 for $D$. rotundata and 0.99 for $D$. alata. The mean time to emergence was 5.7 weeks for $D$. rotundata and 3.0 weeks for $D$. alata, reflecting the difference in vigour between these two species.

The vigour of emergence and subsequent vegetative growth is very critical in yam productivity. Plants that have been weakened, due to extensive sett rotting prior to emergence, will be part of the emergence count, but their vigour is low, and canopy formation is sluggish. The percentage ground cover achieved by such plants is low, and eventual yield is seriously compromised. Yams differ in the rate at which they develop their leaf area. In general, the plant spends the first month or so after emergence concentrating on stem elongation, with relatively little leaf elaboration. The main period of leaf area expansion is in the second and third months after emergence. Thereafter, total leaf area tends to remain steady until plant senescence commences at the end of the season. The proportion ground cover for yams is strongly influenced by cultural practices. In this respect, major differences can arise between staked and unstaked plots, and even between plots using different kinds or methods of staking. When grown without stakes or 
index (LAI) alternating with areas of bare ground. Leaf area may be high, but ground cover is relatively low. Appropriate staking practices can improve the situation. The amount of solar radiation intercepted by the yam crop may be considered as a function of the intensity and duration of the solar radiation, the proportion of ground covered by its green leaves, the leaf area index, and the leaf display. Because of the relatively late development of leaf area in yams, the solar radiation during the entire season may not be as critical as the solar radiation in the second half of the season, when the requisite leaf area is already in place. In some of the more humid parts of the yam-growing regions, persistent cloud cover during the growing season tends to keep total solar radiation relatively low for the duration of crop growth. From this it follows that the proportion of total solar radiation (which consists of about $50 \%$ of photosynthetically active radiation (PAR) between 400 and $700 \mathrm{~nm}$ ) may be described through the following equations:

$$
\mathrm{LAI}=\text { Leaf area per stem } \times \text { Stem density }
$$

Proportion ground cover $=\mathrm{LAI} / x$

This approximative relationship needs to be experimentally established for the particular crop and cultural practices (staking). For potato (Haverkort et al., in press) a value for $x$ of 3 was found to be valid over a number of years and cultivars.

$$
\text { Intercepted solar radiation }=\mathrm{PGC} \times \text { Solar radiation }
$$

Here, PGC means the Proportion of the Ground Covered by green foliage. Equation 8 assumes that $100 \%$ of PAR is actually absorbed by the foliage at $100 \%$ ground cover. Haverkort et al. (in press) found this to be true for potatoes under high latitude conditions. For yam under tropical conditions the relationship still needs to be established.

Various authors have studied leaf area development in yams from different perspectives. Chapman (1965), using D. alata grown in Trinidad, obtained maximum leaf area index values of approximately 4.0 , and leaf area duration values of $37-58$ weeks. The time required to attain the maximum LAI was approximately 17 weeks after emergence. Ground cover was not determined, nor were figures for solar radiation given for the experimental period, although these could be roughly approximated from the general meteorological data for the period. Enyi (1972), on the other hand, worked with D. esculenta in Sierra Leone. He observed unusually high LAI values of 8.5 , attained approximately 20 weeks after emergence. Leaf area per plant was about $4.9 \mathrm{~m}^{2}$ at its peak, and leaf bulking rate in the early 
et al. (1984) for D. rotundata in Nigeria. Onwueme $(1972,1974)$ carried out various leaf area measurements in Nigeria. Using $D$. rotundata, the maximum LAI value was only 1.4 ; this peak LAI was attained approximately 15 weeks after emergence. Maximum leaf area/plant was $1.10 \mathrm{~m}^{2}$ for cultivar Okukunmo and $2.50 \mathrm{~m}^{2}$ for cultivar Agwagwa. Similarly, leaf area measurements on D. alata (Onwueme, 1978b) at approximately 10 weeks after emergence gave values of $0.83 \mathrm{~m}^{2} /$ plant for those raised from small setts, and $3.09 \mathrm{~m}^{2} /$ plant for those from large setts. Neither ground cover nor solar radiation were measured in these experiments. Sobulo (1972) likewise obtained a relatively low value of 2.53 for maximum leaf area index in D. rotundata grown in Nigeria. Ground cover measurements with respect to the yam crop are few in the literature. Oriuwa et al. (1980) followed the development of ground cover with time during two seasons for $D$. rotundata and $D$. alata in Nigeria. For $D$. rotundata, the proportion ground cover attained its peak approximately 15 weeks after emergence, corresponding roughly to the reported time of maximum LAI. However, the highest peak proportions ground cover attained by even the best treatment was only 0.75 , reflecting the poor ability of this species to cover the ground, even in the unstaked condition. For $D$. alata, the maximum ground cover also occurred approximately $14-15$ weeks after emergence, and the maximum proportion ground cover ranged between 0.60 and 0.93 for cultivar Aponmapondenu. Budelman (1990) used a photographic method to determine the proportion ground cover at 9 weeks after planting $D$. alata in the Cote d'Ivoire. At this early stage, he observed proportion ground cover values ranging from $0 \cdot 26$ to $0 \cdot 62$. No subsequent ground cover measurements were carried out for the remainder of the season. Data sets on solar radiation with respect to yam are even more difficult to find. Some measurements done by Kpeglo et al. (1982a) are of marginal value since they were discontinuous and only performed on specific days when other data were being collected. For many experimental locations, approximations made from the general climatological data for the country or region may suffice to give some idea of the ambient conditions of solar radiation.

The total dry matter production is determined by the intercepted radiation and the radiation use efficiency. The partitioning of the dry matter at any given time depends on the developmental stage of the plant. Early in the season, much of the dry matter is utilised for the production of root, vine and leaf material. Tuber initiation usually occurs about two months after emergence. Thereafter, the tuber becomes the most important sink for dry matter, with less preference given to shoot and root tissue. Tuber bulking 
ignore the dry matter which the propagule may contribute directly to the plant and subsequent yield, because the total dry matter of the propagule is small. This is not so for yams. Planted setts may contain $200 \mathrm{~g}$ or more of dry matter, and indeed experimental evidence clearly shows that this large pool of dry matter has profound influence on the vigour and yield of the subsequent plant (Miege, 1965; Onwueme, 1972; Lyonga et al., 1973; Nwoke et al., 1973; Onwueme, 1978b). Moreover, Onwueme (1975b) showed that some of the dry matter of the sett can be translocated directly into the new tuber. The producer is mostly interested, not in the harvest dry weight, but in the marketable fraction of the produced fresh tuber matter. Tuber dry matter content and the proportion of tubers discarded because of unmarketability will then have to be taken into account. To calculate this yield, and to gain information on the tuber size, eqns 9-11 are used:

Tuber fresh matter $=$ Tuber dry matter/Dry matter content

Marketable tuber yield $=$ Marketable fraction $\times$ Tuber fresh matter $\quad(10)$

Mean tuber size $=$ Marketable fresh matter/Tuber number

The time from emergence to tuber initiation is about 9-13 weeks for $D$. rotundata (Onwueme, 1972, 1974; Kpeglo et al., 1982b; Njoku et al., 1984), 8-12 weeks for D. alata (Chapman, 1965; Onwueme, 1978b), and 15 weeks for D. esculenta (Enyi, 1972). However, it has been shown that the earliness of tuber initiation is promoted by increased sett weight (Onwueme, 1978b) and increased physiological age of the sett material (Onwueme, 1975a). Tuber bulking rates determined for $D$. esculenta by Enyi (1972) were $0.101-0.165 \mathrm{~kg}$ fresh wt/plant/week, $1130-1883 \mathrm{~kg}$ fresh wt/ha/week, and $30.2 \mathrm{~g}$ dry $\mathrm{wt} / \mathrm{plant} /$ week, respectively. Corresponding values for $D$. rotundata were $51 \mathrm{~g}$ dry wt/plant/week (Njoku et al., 1984) and $0.3 \mathrm{~kg}$ fresh/plant/week (Kpeglo et al., 1982b). Peak rates of tuber bulking measured by Enyi (1973) ranged from $2435 \mathrm{~kg}$ to $4593 \mathrm{~kg}$ fresh $\mathrm{wt} / \mathrm{ha} /$ week.

\section{DESCRIPTION OF A SET OF MODELS OF INCREASING COMPLEXITY}

Fresh tuber production of a yam crop may be described in several ways. As more observations are carried out on the crop, more comprehensive models may be described and quantified. The simplest model makes use of the linear relation (eqn 12) between the amount of intercepted solar radiation by the canopy (IR) from tuber initiation (IRtub) and fresh tuber mass (Ytf), as was 
intercepted radiation from emergence (IRtot) minus the amount intercepted by the canopy between emergence and tuber initiation (IRini), shown in eqn 13:

$$
\begin{aligned}
\mathrm{Ytf} & =\mathrm{IRtub} \times \mathrm{Etf} \\
\mathrm{IRtub} & =\mathrm{IR} \text { tot }- \text { IRini }
\end{aligned}
$$

where Etf is the slope and thus represents the efficiency for tuber fresh matter production. This model may suffice when the amount of intercepted solar radiation after tuber initiation is the only parameter affected by the environment such as by a defoliating pest or disease or by cultural practices such as an early harvest before maturity. When the dry matter content of the harvested tubers (DMC) is known, the harvested tuber dry matter (Ytd) results from eqn 14 and the tuber fresh matter from eqn 15:

$$
\begin{aligned}
& \mathrm{Ytd}=\mathrm{IRtub} \times \mathrm{Etd} \\
& \mathrm{Ytf}=\mathrm{Ytd} / \mathrm{DMC}
\end{aligned}
$$

where Etd represents the efficiency for the production of tuber dry matter from intercepted solar radiation. A more comprehensive description of crop growth is possible when, in the course of crop development, dry matter yields of other plant parts (stems, leaves, roots) are observed. Total dry matter produced (Ytot) is then calculated according to eqn 16 and the harvest index (HI) follows from eqn 17:

$$
\begin{aligned}
& \text { Ytot }=\text { IRtot } \times \text { Etot } \\
& \mathrm{HI}=\mathrm{Ytd} / \text { Ytot }
\end{aligned}
$$

where Etot represents the efficiency for total dry matter production. If, of a crop, all basic above-mentioned crop growth characteristics are known, the fresh tuber matter may be calculated at any time by eqn 18 :

$$
\mathrm{Ytf}=\mathrm{IRtot} \times \text { Etot } \times[(\text { IRtub } \times \text { Etub }) / \text { Ytot }] / \mathrm{DMC}
$$

Through periodic harvests of crops which receive different treatments, the values of the crop growth parameters shown in eqn 18 are quantified. To increase the understanding of how changes in above-mentioned crop growth parameters are brought about, underlying processes need to be studied in greater detail. Thus, a more mechanistic explanatory model is being realised. In this model, intercepted radiation may be calculated from the leaf area index and an extinction coefficient. Efficiency for dry matter production may also be derived from photosynthetic and respiratory rates of individual leaves. Each crop growth process can be described with equations which best 
The parameters outlined in eqns 1-18 and on the relational diagram (Fig. 1) can be influenced by ecological factors and cultural practices. Phytosanitary and genetic factors may also exert some influence, but they are, at present, kept outside the discussion because these factors are relatively easy to regulate through pest control and choice of cultivar. Temperature, within the range encountered in the yam-producing regions, may affect the time to emergence (i.e. rate of emergence), but not necessarily the final proportion of emergence, except in a few instances where supraoptimal soil temperature encountered after planting may bake the sett and cause poor emergence. Farming strategy for avoiding this situation is the use of mulches. Temperature may also be expected to affect the net dry matter production, through the influence of temperature on leaf growth rate and respiration (radiation-use efficiency). At high ambient temperatures, such as those existing in the yam-producing regions, a large part of the gross dry matter resulting from the intercepted radiation is probably expended in crop respiration. There have been scattered reports in the literature of attempts to measure various metabolic processes related to yield in yams. Kpeglo et al. (1982a) attempted to measure photosynthetic rate in $D$. rotundata leaves by an indirect method. They obtained values of $0.7-1.03 \mathrm{~g}$ dry matter $/ \mathrm{m}^{2}$ of leaf/h for cultivar Ekpe, while for cultivar Nwopoko, the range of values was $0 \cdot 50-0 \cdot 85$.' The rate apparently decreased as the leaf aged. Net assimilation rate (NAR) has often been measured, but there appears to be some discrepancy in what the various authors mean by this term. Values obtained (in $\mathrm{g} / \mathrm{m}^{2}$ of leaf/week) include 16-23 for D. alata in Trinidad (Chapman, 1965 ) and 17 for D. rotundata in Nigeria (Sobulo, 1972). Both values are of the order of one tenth of values for other tropical species reported elsewhere (Blackman \& Black, 1959). Njoku et al. (1984) also report NAR values, but there is apparent discrepancy between the mean value derived from their graph $\left(0.4 \mathrm{~g} / \mathrm{m}^{2} /\right.$ week $)$ and that stated in their text $\left(40 \mathrm{~g} / \mathrm{m}^{2} /\right.$ week $)$. Similarly, Sobulo (1972) expressed some of his NAR values in units of $g / g / w e e k$, obtaining values in the range of $0.43-0.98$ for the latter part of the season. Enyi $(1972,1973)$ found that the relative growth rate of D. esculenta in Sierra Leone was ${ }^{\circ} 0 \cdot 1-0 \cdot 2 \mathrm{~g} / \mathrm{g} /$ week, while the total dry matter bulking rate was approximately $10-70 \mathrm{~g}$ dry $\mathrm{wt} / \mathrm{m}^{2}$ of leaf/week, or about $43.8 \mathrm{~g}$ dry $\mathrm{wt} /$ plant/week. Njoku et al. (1984) reported relative growth rates of $0 \cdot 22-0.80 \mathrm{~g} / \mathrm{g} /$ week for $D$. rotundata. Kpeglo et al. $(1982 b)$ attempted to determine 'dark respiration' for $D$. rotundata, but the methodology used was not sensitive enough and the results are rather unreliable.

Because of the high moisture content of the sett, soil moisture exerts a less profound effect on the early stages of sprouting than would be expected. 
occur. Sprouting under dry soil conditions may, however, increase the mean number of the sprouts per sett, and therefore the mean number of plants per stand (Onwueme, 1976). Of course, soil moisture deficits during the season can result in retarded growth, slow leaf area expansion, and a reduced radiation-use efficiency, resulting in decreased tuber yield on both fresh and dry weight basis. Little research has been carried out on the effects of nutrients on yam crop growth, but their likely effect is on leaf growth, radiation-use efficiency, harvest index, and tuber size. The absolute values of the parameters in the scheme will depend to a large extent on the species and cultivar in question. Slower-growing species (such as D. rotundata or $D$. esculenta) tend to emerge more slowly, attain a smaller total leaf area, have a lower proportion of ground cover and a lower yield than faster-growing species such as D. alata. Within each species, cultivar differences also exist with respect to these parameters (Kpeglo et al., 1982a,b).

\section{INFORMATION GAPS AND RESEARCH NEEDS}

It is clear from the above that, even for the simple model that is proposed here, there are many vital pieces of data that have not been accurately determined and reported in the literature. Reported measurements of leaf area and proportion ground cover are too few and not comprehensive enough; while solar radiation at experimental sites and harvest index have received hardly any attention at all. Even for parameters whose values have been reported, such data have come in bits and pieces from scattered experiments under widely varying conditions. In order to progress with the modelling process, it is important to have data sets in which all the relevant data have been measured in individual comprehensive experiments. It is only in such data sets that the relationship of the parameters to one another can become clear. No such comprehensive experiments have been done, and it is important that such experiments are planned and carried out. Furthermore, there is a need to quantify how the values of the various parameters are influenced by cultural practices, climatological factors, stress, disease, and other yield-reducing factors. Lacking published experimental data, the significance of water and nutrient limitation could not be discussed in any detail. Yet it is obvious from comparison with other crops, that both stress factors, to various degrees, reduce the amount of intercepted solar radiation by the crop, and the conversion efficiency into dry matter. They also likely alter the pattern of dry matter distribution to the different plant organs. Pests and diseases, in most cases, cause symptoms which may be described in 
while foliar diseases may both reduce the foliar mass (and, consequently, the amount of intercepted radiation) and the conversion efficiency of dry matter production. These effects, however, are relatively easy to quantify and to incorporate into the model as proposed in this paper. The irregularity of emergence may prove much more difficult to include since the model uses related data for initialisation. The factors leading to the initial establishment of the crop may need to be studied separately from the factors affecting final tuber yield once the crop has been established.

An attempt was made (Spijkerboer, 1990) to model the growth and productivity of yams in the programming language CSMP, based on available data reported by the authors mentioned in the reference section of this paper. The value of the outcome of such a crude exercise is limited, however, when not backed-up by experimental data to validate the values of the parameters used. At present, a comprehensive set of crop growth, development and climatic data upon which to base a model to be validated, is lacking. When starting to model yam growth, it is of first priority to accumulate data in field trials where yams are grown under optimal conditions. Prioritising further experimental needs will further depend on local constraints. If production constraints are related to temperature, drought, lack of nutrients or to the presence of diseases, it is clear that research at specific locations will be carried out with such specific aims in mind. The research priorities will then determine the degree of detail of the model with regard to the specific constraint studied under the experimental conditions of the specific site.

Looking ahead to the more complex models than the one proposed here, it is clear that there are numerous fundamental physiological parameters that have yet to be clearly determined for yams. Even such fundamental questions as to whether the crop is a $\mathrm{C} 3$ or $\mathrm{C} 4$ plant have yet to be definitively answered for yam. Measurement of photosynthetic rate, net assimilation rate, dry matter partitioning, water use efficiency, transpiration rate, and water relations need to be carried out in comprehensive experiments under controlled conditions. One peculiar feature in the case of yam, that must be unravelled by experimentation, is the influence which the initial sett weight exerts on various other parameters, and on eventual tuber yield. Even though some information is already available on how this effect is exerted (Onwueme, 1972, 1974, 1978a) much more still needs to be known about it.

It is proposed that future experimentation on yam growth and development should be carried out along the framework presented in this paper. The minimum amount of data to be gathered are shown in the 
understanding of the growth and development of the yam crop. It is shown that individual experiments as carried out in the past, although they may give an answer to specific questions, have not substantially broadened the knowledge of the crop; they are not useful for predicting yields under conditions which differ from the sites where the experiments were carried out. Site-specific research will still be needed to elucidate problems which the crop may suffer (e.g. lack of nutrients, pests, diseases), or the influence of cultural practices such as sett weight, spacing, and staking. With additional data collection on crop parameters other than yield components, and with adequate description of environmental data (e.g. solar radiation, temperature and rainfall), such experimentation will find a wider application in the future. This paper has highlighted the need for modelling yam growth and productivity, and has proposed a simple model for the purpose. Even for this simple model, there is an abject lack of comprehensive data sets for purposes of quantification. If the modelling process is to progress further, it is essential to perform experiments from which complete data sets can be obtained.

\section{ACKNOWLEDGEMENT}

The authors wish to thank Professor M. Flach and Professor R. Rabbinge for assistance rendered during the conception and execution of this work.

\section{REFERENCES}

Blackman, G. E. \& Black, J. N. (1959). Physiological and ecological studies in the analysis of plant environment. XII. The role of the light factor in limiting growth. Annals of Botany, N.S., 23(89), 131.

Budelman, A. (1990). Woody legumes as live support systems in yam cultivation. II. The yam-Gliricidia sepium association. Agroforestry Systems, 10, 61-9.

Chapman, T. (1965). Some investigations into factors limiting yields of the White Lisbon yam (Dioscorea alata L.) ounder Trinidad conditions. Tropical Agriculture (Trinidad), 42, 145-51.

Coursey, D. G. (1967). Yams, Longman, London, 230 pp.

Enyi, B. A. C. (1972). The effects of seed size and spacing on growth and yield of lesser yam (Dioscorea esculenta). J. Agric. Sci., Cambridge, 78, 215-25.

Enyi, B. A. C. (1973). The effect of time of planting and nitrogen application on growth, development and yield of lesser yam (Dioscorea esculenta). Nigerian Journal of Science, 7, 93-103.

FAO (Food \& Agricultural Organization of the United Nations) (1989). Production

Yearbook, 42, 1988. 
Haverkort, A. J., Uenk, D., Veroude, H. \& van de Waart, M. (1991). Relationships between ground cover, intercepted solar radiation, leaf area index and infrared reflectance of potato crops. Potato Research, 34, in press.

Kpeglo, K. D., Obigbesan, G. O.\& Wilson, J. E. (1982a). Physiological studies on the white yam, Dioscorea rotundata Poir. I. Influence of plant age and leaf position on photosynthesis and dark respiration. Beitrage trop. Landwirtsch. Veterinarmed., 20, 15-21.

Kpeglo, K. D., Obigbesan, G. O. \& Wilson, J. E. (1982b). Physiological studies on the white yam, Dioscorea rotundata Poir. II. Influence of plant age and leaf position on photosynthesis and dark respiration. Beitrage trop. Landwirtsch. Veter20, 23-9.

Lyonga, S. N., Fayemi, A. A. \& Agboola, A. A. (1973). Agronomic studies in edible yams (Dioscorea spp.) in the grassland plateau region of the United Republic of Cameroon. Paper presented at the Third International Symposium on Tropical Root Crops, Ibadan, Nigeria, 2-9 December 1973.

Martin, F. W. \& Degras, L. (1978). The Tropical Yams and their Potential. Part 5. Dioscorea trifida. USDA, $26 \mathrm{pp}$

Miege, J. (1965). Influence de quelques caracteres des tubercles semencessur la levee et le rendement des ignames cultivees. J. Agric. Trop. Bot. Appl., 4, 315-42.

Njoku, E., Nwoke, F. I. O. \& Okonkwo, S. N. C. (1984). Pattern of growth and development in Dioscorea rotundata Poir. Tropical Agriculture (Trinidad), 61 17-19.

Nwoke, F. I. O., Njoku, E. \& Okonkwo, S. N. C. (1973). The effect of size of seed yams on yield of individual plants of Dioscorea rotundata. Paper presented at the Third International Symposium on Tropical Root Crops, Ibadan, Nigeria, 2-9 December 1973

Okoli, O. O., Igbokwe, M. C., Ene, L. S. O. \& Nwokoye, C. (1982). Rapid multiplication of yam by the minisett technique. Research Bulletin No. 2, National Root Crops Research Institute, Umudike, Nigeria, $12 \mathrm{pp}$

Onwueme, I. C. (1972). Influence of weight of the planted tuber on the vegetative performance of white yam (Dioscorea rotundata, Poir.) plants. Niger. Agric. Journal, 9, 170-3.

Onwueme, I. C. (1974). Leaf area development in white yam (Dioscorea rotundata Poir) as affected by kinetin treatment. Niger. Agric. Journal, 11(3), 17-22.

Onwueme, I. C. (1975a). Influence of storage time on earliness of sprouting and tubering in Dioscorea rotundata yams. J. Agric. Sci., Cambridge, 84, 503-5.

Onwueme, I. C. (1975b). Tuber formation in yam (Dioscorea spp.): Effect of moisture stress; contribution of the parent sett. J. Agric. Sci., Cambridge, 85, 267-9.

Onwueme, I. C. (1976). Performance of yam (Dioscorea spp.) planted without water. J. Agric. Sci., Cambridge, 87, 413-15.

Onwueme, I. C. (1978a). The Tropical Tuber Crops: Yams, Cassava, Sweet Potato, Cocoyams. John Wiley \& Sons, Chichester, $234 \mathrm{pp}$.

Onwueme, I. C. (1978b). Sett weight effects on time of tuber formation, and on tuber yield characteristics, in water yam (Dioscorea alata L.). J. Agric. Sci., Cambridge, 91, 317-19.

Onwueme, I. C. (1984). Thc physiology of yams. In Physiology of Tropical Field Crops, ed. P. Goldsworthy \& N. Fisher. John Wiley \& Sons, Chichester, $669 \mathrm{pp}$ 
spp.) production through weed control with herbicides, the elimination of staking, and cropping at high density. J. Agric. Sci., Cambridge, 95, 641-54.

Oriuwa, L. O. \& Onwueme, I. C. (1980). Determining the optimum spacing for growing yam (Dioscorea spp.) without stakes. Quarterly Journal of International Agriculture, 19, 5-24.

Sobulo, R. A. (1972). Studies on the white yam (Dioscorea rotundata) I. Growth analysis. Experimental Agriculture, 8, 99-106.

Spijkerboer, H. (1990). Modelling the growth and productivity of yams (Dioscorea spp.) in the programming language CSMP. Internal Report, Departments of Tropical Crop Science and Theoretical Production Ecology, Agricultural University Wageningen, The Netherlands, $23 \mathrm{pp}$. 